RFP-2300

March 28, 1974

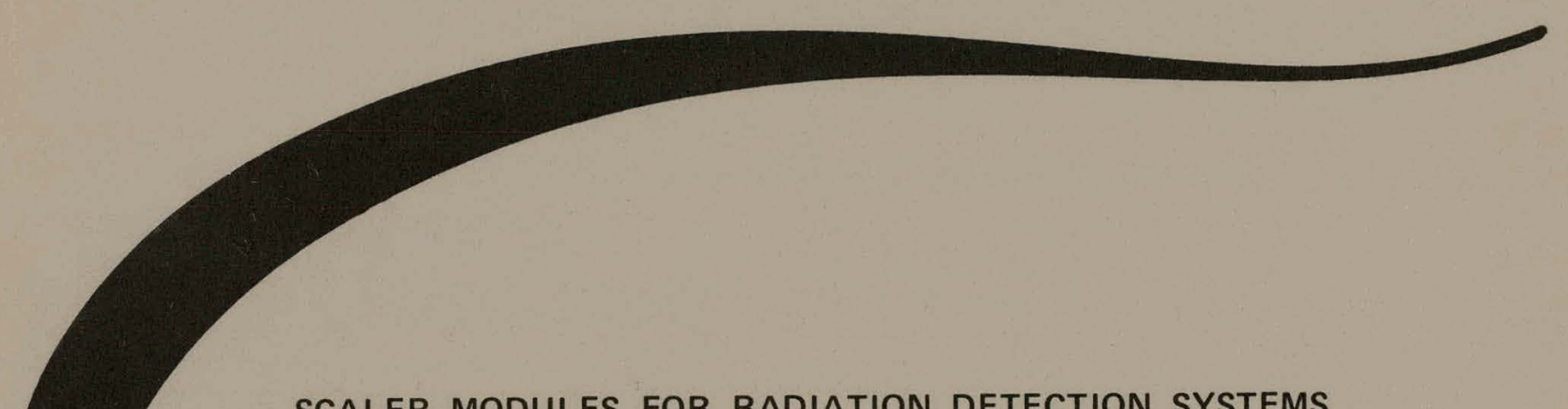

SCALER MODULES FOR RADIATION DETECTION SYSTEMS

Bradley E. Martin



DOW CHEMICAL U.S.A.

ROCKY FLATS DIVISION

P. O. BOX 888

GOLDEN, COLORADO 80401

U. S. ATOMIC ENERGY COMMISSION CONTRACT AT(29-1)-1106 


\section{DISCLAIMER}

This report was prepared as an account of work sponsored by an agency of the United States Government. Neither the United States Government nor any agency Thereof, nor any of their employees, makes any warranty, express or implied, or assumes any legal liability or responsibility for the accuracy, completeness, or usefulness of any information, apparatus, product, or process disclosed, or represents that its use would not infringe privately owned rights. Reference herein to any specific commercial product, process, or service by trade name, trademark, manufacturer, or otherwise does not necessarily constitute or imply its endorsement, recommendation, or favoring by the United States Government or any agency thereof. The views and opinions of authors expressed herein do not necessarily state or reflect those of the United States Government or any agency thereof. 


\section{DISCLAIMER}

Portions of this document may be illegible in electronic image products. Images are produced from the best available original document. 


\section{LEGAL NOTICE}

This report was prepared as an account of work sponsored by the United States Government. Neither the United States nor the United States Atomic Energy Commission, nor any of their employees, nor any of their contractors, subcontractors, or their employees, makes any warranty, expressed or implied, or assumes any legal liability or responsibility for the accuracy, completeness or usefulness of any information, apparatus, product or process disclosed, or represents that its use would not infringe privately owned rights.

Printed in the United States of America

Available from the

National Technical Information Service

U. S. Department of Commerce

Springfield, Virginia 22151

Price: Printed Copy $\$ 4.00$ Microfiche $\$ 1.45$ 


\title{
SCALER MODULES FOR RADIATION DETECTION SYSTEMS
}

\author{
Bradley E. Martin
}

Product and Health Physics Research

\section{ELECTRONICS GROUP}

Modules for Radiation Detection Systems and related items will be grouped in a series of reports beginning with RFP. 2300 through RFP-2325. RFP-2300 represents the first report in the series.



\section{SUBJECT DESCRIPTORS}

DOW CHEMICAL U.S.A. ROCKY FLATS DIVISION

P. O. $80 \times 888$

GOLDEN, COLORADO 80401

Prepared under Contract AT(29-1)-1106

for the

\section{Scaler Modules}

Alpha Detection Systems

Wound Counting Systems

Gamma Spectrometers

Electronics

Monitoring Systems

Nuclear Instrumentation BIN

Albuquerque Operations Office

U. S. Atomic Energy Commission

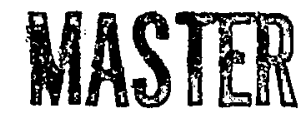




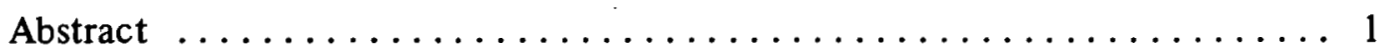

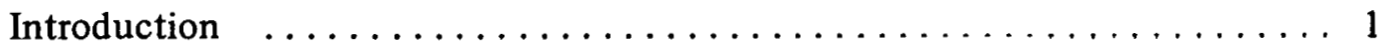

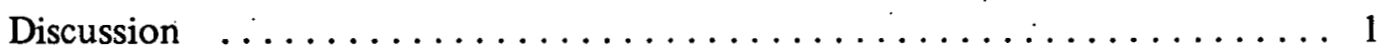

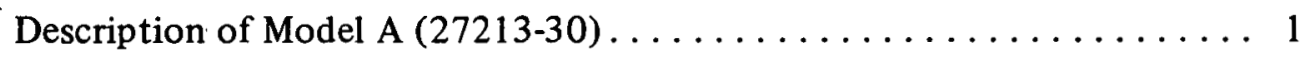

Description of Model B $(24370-31) \ldots \ldots \ldots \ldots \ldots \ldots \ldots$

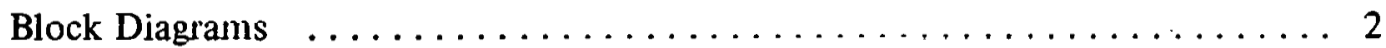

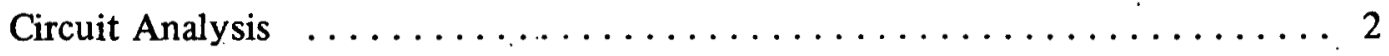



Model A (27213-30) $\ldots \ldots \ldots \ldots \ldots \ldots \ldots \ldots \ldots \ldots$

Model B $(24370-31) \quad \ldots \ldots \ldots \ldots \ldots \ldots \ldots \ldots \ldots \ldots \ldots$

Servicing of Modules $\ldots \ldots \ldots \ldots \ldots \ldots \ldots \ldots \ldots \ldots$

Illustrations, Figures 1 through $13 \ldots \ldots \ldots \ldots \ldots \ldots$ 
RFP-2300

\title{
SCAALER MODULES FOR RADIATION DETECTION SYSTEMS
}

\author{
Bradley E. Martin
}

\begin{abstract}
In developing radiation detection instrumentation at Rocky Flats, a system concept using plug-in modules was planned. Losses of operational time due to maintenance are drastically reduced as a malfunctioning module can be replaced within minutes. Versatility is another advantage of the modular concept and a particular module can be used in many different system designs. A significant cost savings in system development can also be realized.
\end{abstract}

The scalers described are housed in one-wide Nuclear Instrumentation Bin (NIM-BIN) modules. The design incorporates the latest in COS/MOS (complementary symmetry metal-oxide semiconductor) integrated circuitry, featuring low power, low cost, and high reliability.

These modules were developed specifically for radiation detection systems. Model 24370-31 is used in gross alpha detection systems. Model 27213-30 appears in a medical wound-counter system, but can be used also in a gamma spectrometer system, or in other related systems.

Operational procedures and servicing of units are included.

\section{INTRODUCTION}

Two scaler modules are described. Model 24370-31, referred to as Model B for clarity, was developed for gross alpha detection systems and Model 27213-30, Model A, was developed for a medical wound-counter system, a gamma spectrometer system, and other related applications.

The scalers offer capabilities in collecting data analyzed for levels of radioactive contamination which might occur during plant activities. Under the Health Physics monitoring program at Rocky Flats Plant, concerted efforts are directed toward improvements in safety, stateof-the-art applications, and the reduction of operating costs.

\section{DISCUSSION}

Description of Model A (27213-30):

Model A (27213-30) is a scaler module that can be used as a counter and storage module in most any electronic data-accumulating system. Two specific instruments in which the module is now being used are a medical wound-counter system and a gamma spectrometer system. Positive logic pulses varying from 3 volts to 10 volts in amplitude can be applied to the scaler input.

The complete modules are shown in Figure $1 .^{1}$ The interior view of Model A is given in Figure 2 and the rear view in Figure 3. This module contains two printed circuit boards (PCB): the scaler PCB and readout PCB.

Located on the scaler PCB are six COS/MOS integrated circuit (IC) decade-divider counters. Associated with these counters are six bipolar IC transistor arrays. These are used as current boosters for driving the readout PCB, as the COS/MOS IC does not have this capability.

\footnotetext{
${ }^{1}$ Illustrations follow at end of text.
} 
The MAN-64A seven-segment light-emitting diode (LED) displays are located on the readout PCB. The readout PCB is joined to the scaler PCB at a right angle by a unique connector. The connector eliminates the massive cable harnesses that are common to many such units.

The scaler and readout assembly are mounted to the right side rails of the module case with two screws. All circuitry is accessible for easy maintenance.

The front panel is a black magic type display, made of red translucent plastic. The back side of the panel is painted flat black with exception of the LED viewing area. Normally the panel appears dark, but when the LEDs are illuminated, they show through the plastic and provide a clearly visible and eye-pleasing display.

On the rear panel (see Figure 3), a BNC receptacle serves as the input connection for the module.

\section{Description of Model B (24370-31):}

Model B (24370-31) is a scaler module primarily used in gross alpha-detection systems. It is capable of counting the pulses directly from the anode of a photomultiplier tube aftixed with a zinc sulfide scintillator. This module appears similar to Model A (27213-30). As noted in Figure 4, Model B (24370-31) contains three $\mathrm{PC} B$ s and is an expanded version of the first scaler. The same PCB scaler and readout are used, however the scaler on the second module includes a transistor-transistor-logic (TTL) monostable multivibrator IC at the input. This particular circuit serves as a discriminator and pulse standardizer.

A high voltage power supply appears as the third PCB. It is a regenerative feedback oscillator circuit, variable from 800 to 1200 volts DC. On the rear panel of this module is a BNC receptacle for connection to a photomultiplier tube detector.
In addition, a high voltage adjustment and a test point are provided (see Figure 5).

\section{BLOCK DIAGRAMS}

Figure 6 shows a block diagram of Model A (27213-30). The 2.5 volts AC powers the LED readout display and the +5 volts $D C$ powers the IC circuitry.

The reset and enable functions must be supplied by an external module. The reset line is normally low (zero volts). When the reset line is forced high ( +5 volts), the LEDs on the readout PCB $317-01004 \mathrm{~A}$ display the digit, 8 . This serves as a lamp-test function and insures that all segments of the MAN-64As will display. When the reset line relurns low, the decade counters on the scaler PCB-320-01014 are reset to zero.

The enable line is normally low and must go high before the scaler circuitry is permitted to count input pulses appearing at Terminal 6 .

Figure 7 shows a block diagram of Model B (24370-31). Power and control functions are the same as described for Model A. The high voltage power supply PCB 317-01005 is adjustable and normally set to about 900 volts. The voltage can be more precisely set by determining the operating plateau of the photomultiplier tube being used. The high voltage potential from Terminal 5 appears at the test point (TP) and the photomultiplier tubc (PMT) receptacle. The signal pulses produced by the PMT delector are fed back on the same line to Terminal 1 of the scaler PCB.

\section{CIRCUIT ANALYSIS}

Figure 8 shows a schematic diagram of Model A (27213-30). Input pulses are applied to Terminal 1. It should be pointed out that the scaler 
PCB 320-01014 is used in both models. In Model $A$, the $A 1$ is not used and a jumper wire is placed between Pin 5 and Pin 6 of Al's position. This couples the input pulses from $R 1$, D1 to Pin 1 of A2. Approximately 3 volts are necessary to trigger A2 and R1 and D1 limit the maximum voltage at Pin 1 of A2 to 4.7 volts in order to protect the internal circuitry of $\mathrm{A} 2$.

A six-decade ripple counter is formed by $\mathrm{A} 2$ through $\mathrm{A} 7$ providing a maximum counting range of 999,999 . The decade counters used are COS/MOS CD4033 AE ICs with decoded seven-segment display outputs and zeroblanking. Pin 3 of A2 is the zero-blanking output and it connects to Pin 4 of A3. The zero-blanking function keeps the readout from displaying nonsignificant zeros. Pin 5 of A2 is the carry out and connects to Pin 1 of A3. It provides one output pulse for every ten input pulses. Only the first decade of counting is shown for simplicity as the other five are typical. Pin 2 of A2 is the enable input and Pin 15 is the reset input. Since the lamptest (LT) function is performed in conjunction with the reset function, Pin 14 of A2, which is the lamp-test input connects to the reset input.

The decoded seven-segment outputs from A2 are fed to A8. In like manner, the outputs from A3 are coupled to A9. This is typical for all decades. Integrated circuits A8 through A13 are transistor arrays which provide the necessary drive current for displaying the MAN-64As. The letters A through G represent the MAN-64A segments.

Capacitors $\mathrm{Cl}$ and $\mathrm{C} 4$ provide proper filtering as recommended for COS/MOS circuitry.

Figure 9 illustrates a component layout for the Model A scaler and readout PCBs. A pin description for the MAN-64A is also given.

Figure 10 shows a schematic diagram for Model B (24370-31). The circuitry of A2 through A13 is the same as described for Model A. The circuit of Al, a TTL monostable multivibrator, functions in this model as a discriminator and pulse standardizer. Negative pulses varying in amplitude are coupled through $\mathrm{C} 2$ and applied to Pin 5 of A1. With $\mathrm{R} 1$, a $10-\mathrm{K}$ ohm resistor $(\mathrm{K}=1000)$, the input pulses must exceed 200 millivolts in order to trigger A1. Capacitor C3 determines the output pulse width of A1, Pin 6 . The output A1, Pin 6, triggers A2.

Figure 11 shows a component layout for the scaler and readout PCB used in Model B (24370-31).

The high voltage power supply used in Model B is noted in Figure 12. Components, Q1, T1, $\mathrm{C} 2, \mathrm{C} 3, \mathrm{R} 1, \mathrm{R} 2$, and the external $10-\mathrm{K}$ ohm potentiometer form. a regenerative feedback oscillator. Diodes D1 through D3 and C4 through $\mathrm{C} 6$ form a voltage tripler. Resistors $\mathrm{R} 3$ through $\mathrm{R} 5$ and $\mathrm{C} 7$ through $\mathrm{C} 9$ filter the pulsating DC voltage from D3. Resistors R6 through $\mathrm{R} 10$ make up a bleeder network to discharge $\mathrm{C} 7$ through $\mathrm{C} 9$ when power is removed. Resistors R11 and R12 are load resistors for the external detectors.

Figure 13 gives the component layout of the high voltage power supply PCB 317-01005 for Model B.

\section{OPERATING PROCEDURES}

The following procedures and requirements are recommended for use with the scaler modules described.

Model A (27213-30):

1. Plug module into NIM-BIN.

a. Power requirements:

(1) +5 volts DC, Pin 27

(2) 2.5 volts AC, Pin 26 
b. Control requirements:

(1) Reset, Pin 22 (Normally Low, Zero Volts)

(2) Enable, Pin 24 (Normally High, Plus 5 Volts)

2. Connect input signal to BNC connector on rear Panel of module.

3. Turn on NIM-BIN power.

4. Scaler is ready for operation.

Model B (24370-31):

1. Plug module into NIM-BIN.

a. Power requirements:
(1) +5 volts DC, Pin 27
(2) 2.5 volts $A C$, Pin 26

b. Control requirements:

(1) Reset, Pin 22 (Normally Low, Zero Volts)

(2) Enable, Pin 24 (Normally High, Plus 5 Volts)

2. Connect photomultiplier tube assembly (approximately 100 meg-ohm impedance) to BNC connector on rear panel of module.

3. Turn on NIM-BIN power.

4. Adjust high voltage (normally set 875 to 925 volts).

A more precise setting can be achieved by running a high voltage plateau curve for each detector tube used.

5. Scaler is ready for operation.

\section{SERVICING OF MODULES}

The chart has been included as a troubleshooting guide to assist in the performance of unscheduled maintenance.

MODEL A (27213-30) AND MODEL B (24370-31)

Problem

Cause

No lamp test

No reset
1. No 2.5 volts, $\mathrm{AC}$

2. Nó +5 volts, DC

3. Short on reset line (faulty CD4033AE)

One or more MAN-64A 1. Burned out segment of segments, do not light with lamp test MAN-64A

2. Faulty CA3081

3. Faulty CD4033AE

Does not count during the enabled interval

1. Faulty CD $4033 \mathrm{AE}$

2. Faulty MC74121P (Model B, 24370-31 only)

3. No high voltage (Model 24370-31 only)

Counts continuously even when disabled

1. Short on enable line (faulty CD4033AE)

2. Faulty MC74121P (Model 24370-31 only)

No high voltage (Model B, 24370-31 only)
1. Faulty $Q 1$

2. D1, D2, or D3 Open 
RFP-2300



FIGURE 1. Front View of Scaler Modules.

17698-9

FIGURE 2. Interior View of Model A (27213-30).

17698-2

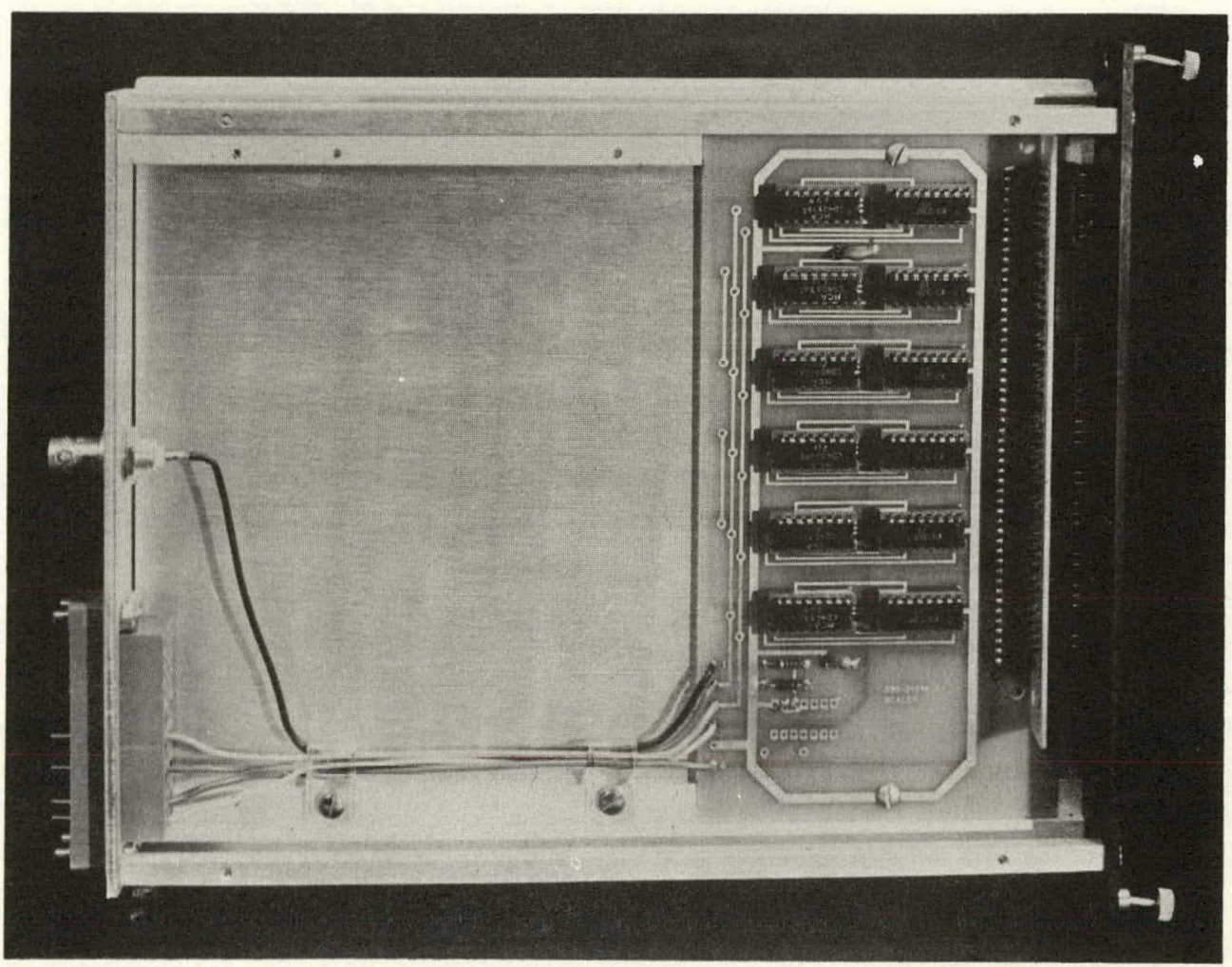


RFP-2300

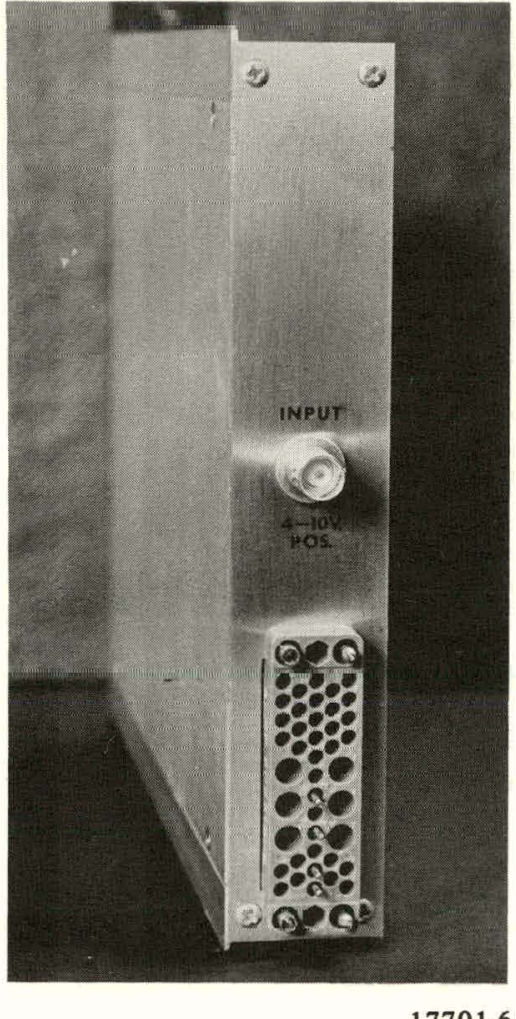

$17701-6$

FIGURE 3. Rear View of Model A (27213-30).

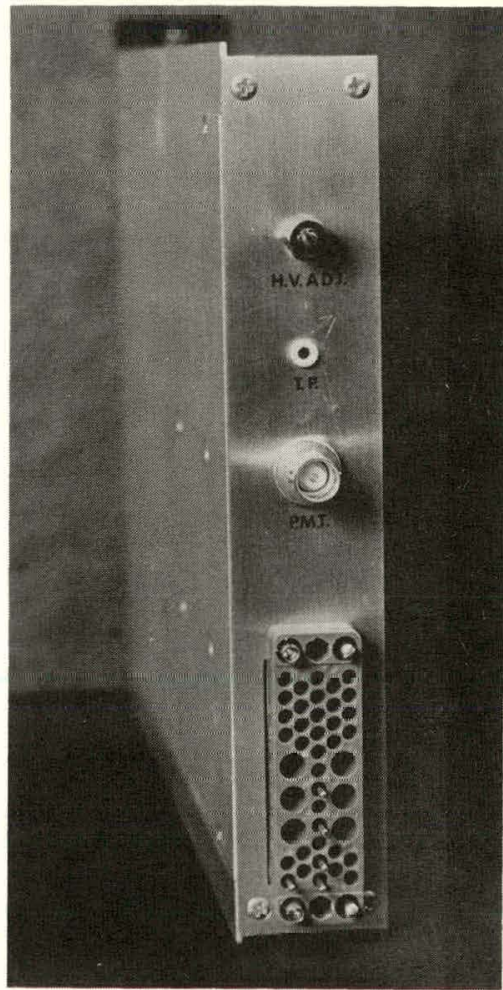

17701-8

FIGURE 5. Rear View of Model B (24370-31).

FIGURE 4. Interior View of Model B (24370-31).

$17648-3$

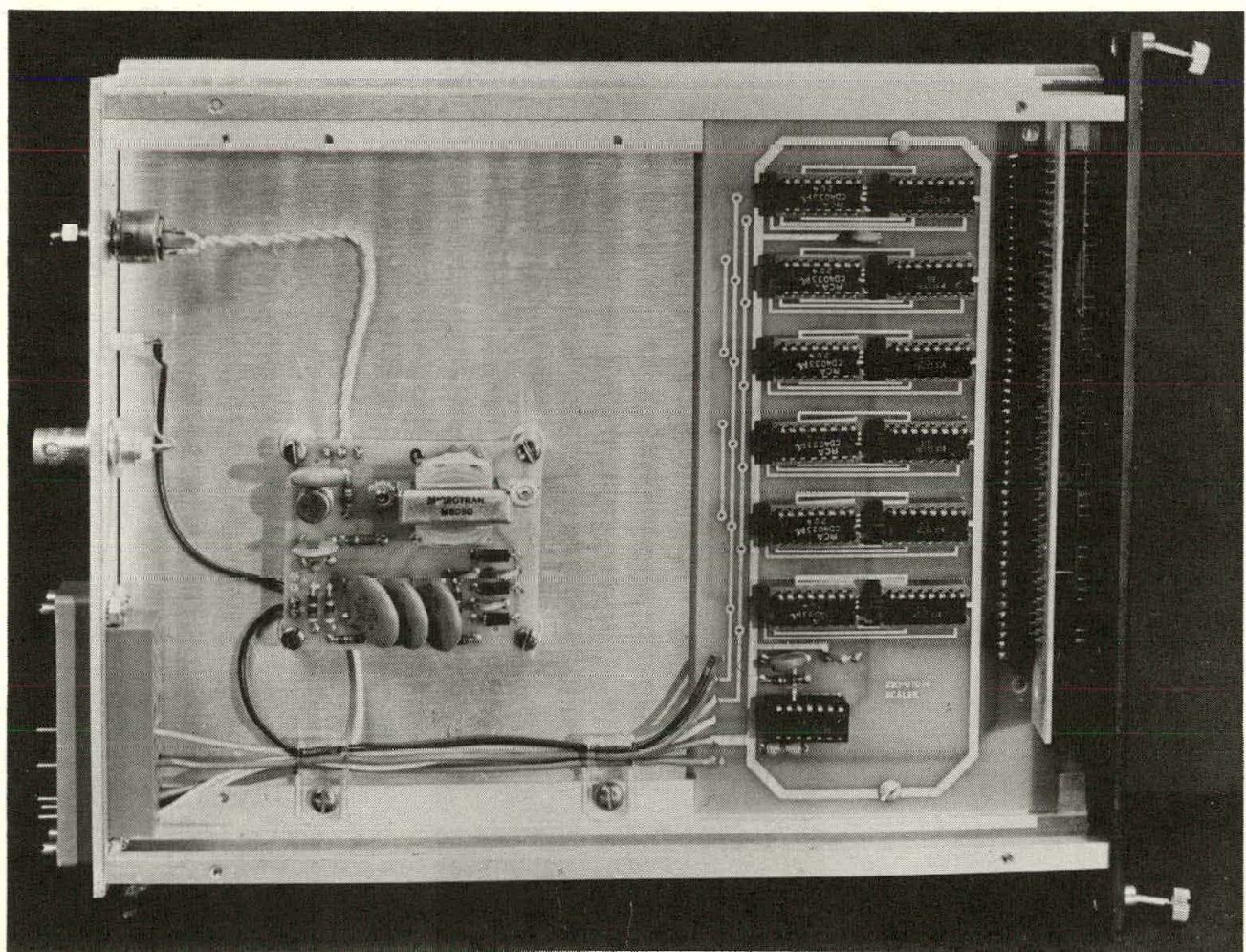






FIGURE 6. Block Diagram of Model A (27213-30) Scaler. 




FIGURE 7. Scaler Block Diagram of Model B (24370-31), 




FIGURE 8. Scaler Circuit Schematic of Model A (27213-30). 


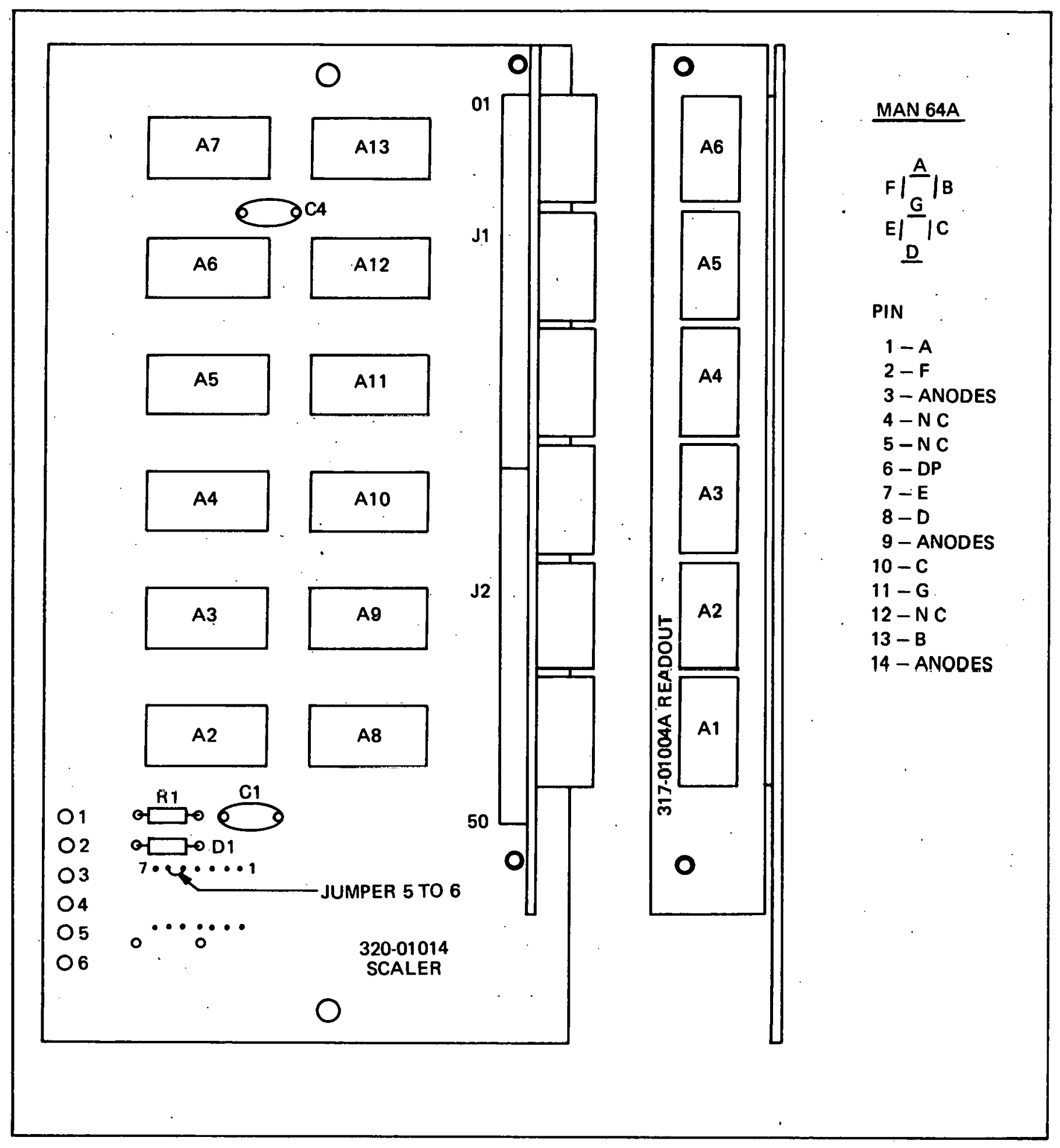

FIGURE 9. Model A Component Layout. 


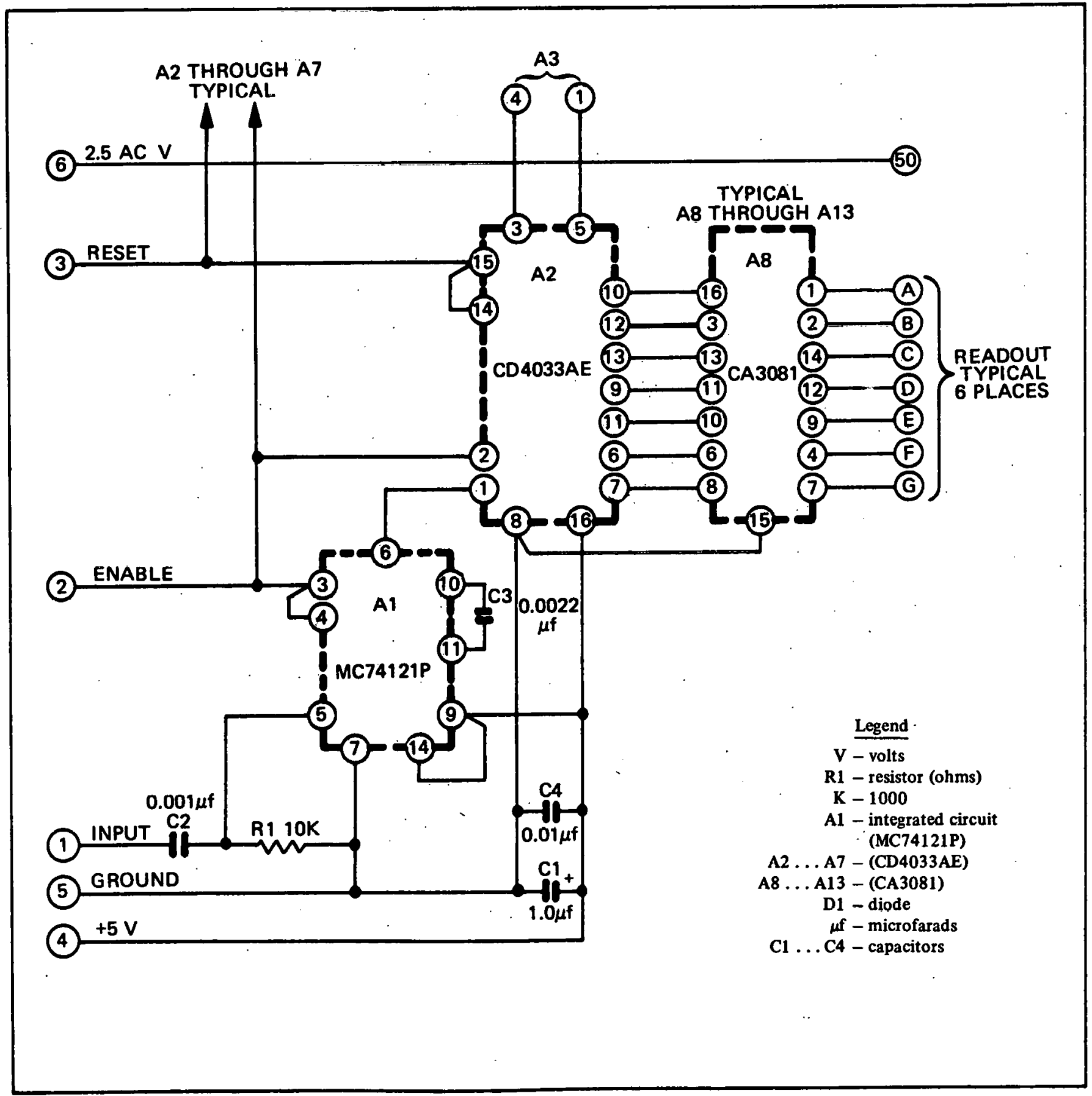

FIGURE 10. Scaler Circuit Schematic of Model B (24.370-31), 


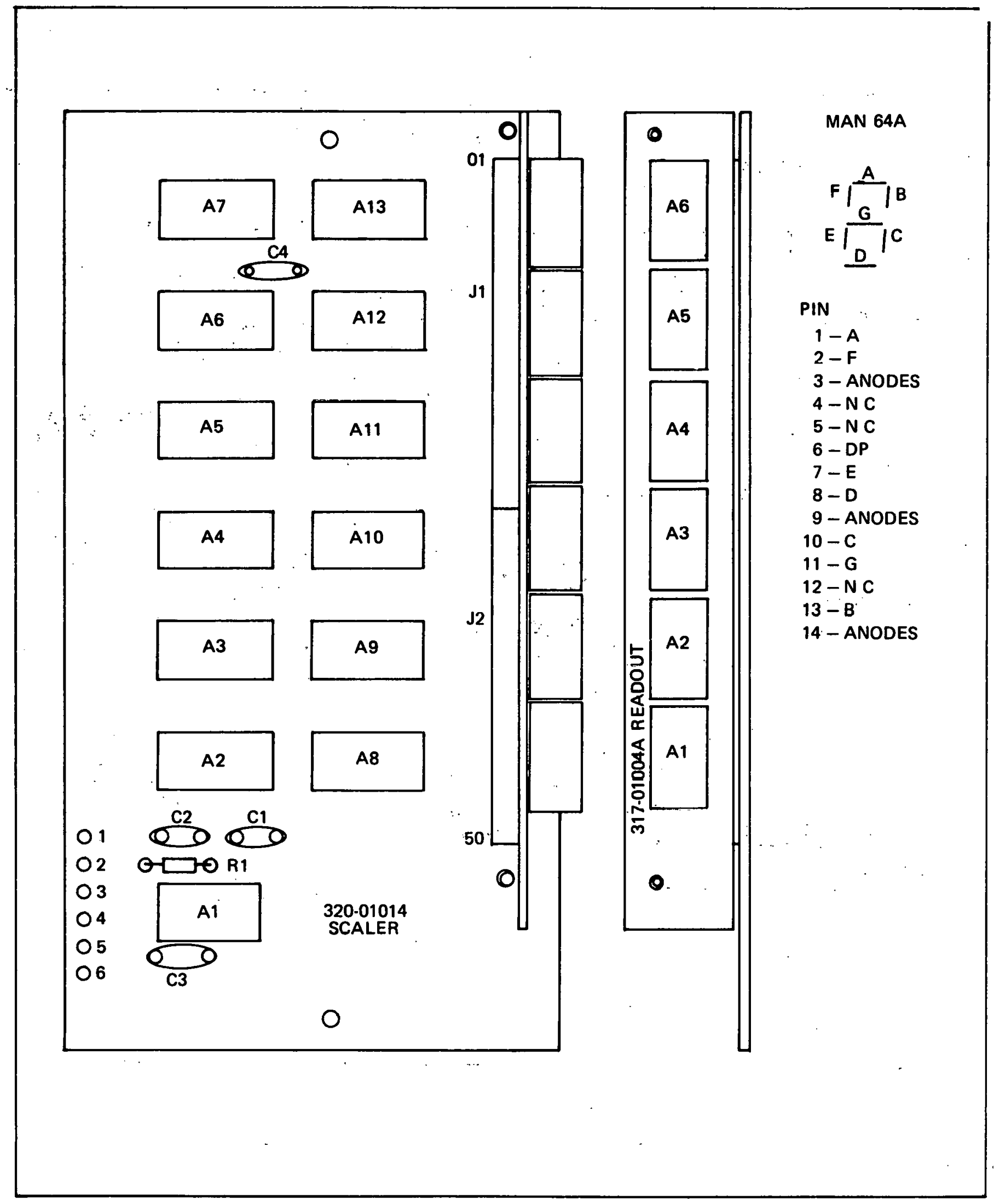

FIGURE 11. Model B Component Layout. 


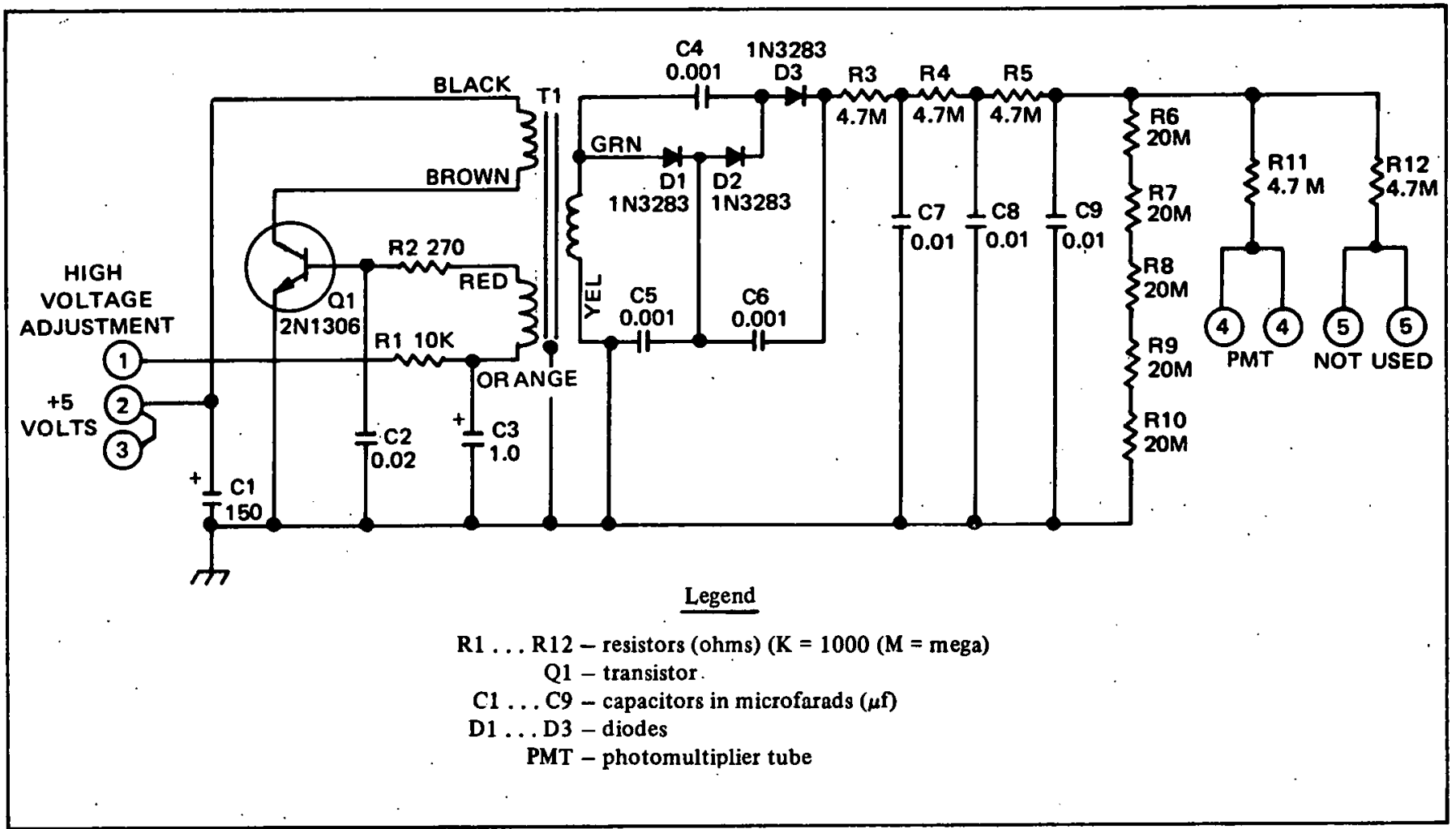

FIGURE 12. Model B Schematic of High Voltage Power Supply.

FIGURE 13. Component Layout for Voltage Supply of Model B.




RFP-2300 